\title{
Spectral Analysis of Diaphragmatic EMG during the Neonatal Biphasic Hypoxic Ventilatory Response
}

\author{
J. F. WATCHKO, W. A. LAFRAMBOISE, D. E. MAYOCK, T. A. STANDAERT, AND
}

D. E. WOODRUM

Department of Pediatrics, Division of Neonatal and Respiratory Diseases, University of Washington, Seattle, Washington 98195

\begin{abstract}
The newborn infant monkey consistently demonstrates a biphasic ventilatory response to hypoxemia. We have previously shown that the ventilatory depression during the late portion of this biphasic response is secondary to a decline in inspiratory volume that cannot be explained solely by central neural depression. We hypothesized that hypoxemia caused the diaphragm to fatigue, thereby accounting for the late ventilatory depression during the biphasic neonatal hypoxic response. Diaphragmatic fatigue has been reported to be associated with a decrease in the centroid frequency $(\mathrm{Fc})$ of the electromyogram derived through frequency spectral analysis. Therefore, we analyzed the power spectral density of the diaphragmatic electromyogram recorded from percutaneously implanted crural diaphragmatic electrodes in five 2-day-old infant monkeys while they breathed room air and after $5 \mathrm{~min}$ exposure to two levels of hypoxemia during the late ventilatory depression. A fast Fourier transform of EKG free diaphragmatic electromyogram was used to compute the power spectral density and the Fc. The Fc during room air breathing was statistically equivalent to the $\mathrm{Fc}$ observed after five minutes exposure to $12 \% \mathrm{FiO}_{2}(p=$ $0.79)$, and $8 \% \mathrm{FiO}_{2}(p=0.74)$ when ventilation was falling. In conclusion, our data demonstrate that changes in the centroid frequency are not present during the biphasic ventilatory decline that occurs with the hypoxic ventilatory response in newborn monkeys. Thus, diaphragmatic fatigue, as defined by a decline in $\mathrm{Fc}$, does not occur during the neonatal biphasic hypoxic response. (Pediatr Res 21: 238-241, 1987)
\end{abstract}

Abbreviation

Fc, centroid frequency

The hypoxic ventilatory response of the human neonate and the newborn of other animal species is characterized by a transient increase in minute ventilation followed by a return to baseline values despite the continued presence of arterial hypoxemia (1-5). Recent studies performed in subhuman primates and kittens have shown that the ventilatory decline cannot be attributed solely to central neural depression since diaphragmatic

Received August 7, 1986; accepted October 17, 1986.

Address correspondence and reprint requests to Jon F. Watchko, M.D., Division of Neonatal and Respiratory Diseases, Department of Pediatrics, RD-20, University of Washington, Seattle, WA 98195.

Supported in part by Public Health Service Grants NIH HL19187 and MCH 000955 . and phrenic neural activity remain elevated even as ventilation falls $(1,4)$.

Data collected on the newborn monkey suggest that the biphasic ventilatory pattern may result from changes in respiratory mechanics (6). A fall in dynamic lung compliance and an increase in functional residual capacity occur during the late portion of the ventilatory decline (6). These changes could account for a reduction in inspired volume for a given level of neural drive in that the lung is less distensible and the diaphragm a less efficient pressure generator at higher lung volume. Consistent with this hypothesis is the fact that the late ventilatory decline during hypoxia is due to a fall in tidal volume $(4,6)$. Diaphragmatic contractility may also be impaired by hypoxemia beyond that attributable to a shift in length-tension status. Specifically, acute hypoxemia has been reported to depress diaphragmatic forceoutput in the neonatal piglet (7). These data raise the possibility that hypoxemia causes the diaphragm to fatigue, thereby accounting for the late ventilatory depression during the biphasic neonatal hypoxic response.

Diaphragmatic fatigue has been reported to be associated with a decrease in the $\mathrm{Fc}$ of the electromyogram derived through frequency spectral analysis (8). Therefore, we analyzed the power spectrum of the crural diaphragmatic electromyogram to calculate the centroid frequency of infant monkeys during the biphasic hypoxic ventilatory response. We hypothesized that the late ventilatory decline during the biphasic neonatal hypoxic response is associated with a decrease in the numeric value of the Fc, indicating diaphragmatic fatigue.

\section{METHODS}

Eight Macaca nemestrina infants were delivered by cesarian section at 160 days of gestation $(0.95$ term) at which time an umbilical artery cannula was placed. All infants were healthy in appearance and had normal blood gases and respiratory rates during the $36-48 \mathrm{~h}$ prior to study.

The infant monkeys were instrumented and monitored as previously described (4). Briefly, a flexible, nonkinking tracheostomy tube of latex rubber was placed on the morning of the study under a light dose of ketamine anesthesia $(5 \mathrm{mg} / \mathrm{kg})$. The subjects were then put in a prone position on a sponge rubber mattress molded to their shape which allowed the infant the freedom to raise its head and limited movement of its appendages. A humidified gas flow (1.5 liter/min) was provided through a T-piece connected to the tracheal tube opening and during inspiration, tidal volume was obtained as the integral of the flow decrease sensed downstream by a hot-wire anemometer (9).

Two insulated stainless steel wires $(0.01$ inch diameter) were percutaneously placed in the crural diaphragm of our subjects 
under local anesthesia (chloroprocaine $\mathrm{HCl}$ ) (10). A third electrode was placed subdermally at the base of the buttocks to provide an electrical ground. Clear, strong signals indicated the electrodes were contained within the crura, $4 \mathrm{~mm}$ or less from another as documented by postmortem examination.

Electromyographic signals were recorded differentially to ground and amplified 5000 to 10,000 times on a Grass preamplifier (P511J) prior to recording on an FM tape recorder (Honeywell $5600 \mathrm{C}$ ). The EMG signal was processed utilizing a Service Associates 414 Analog Processor where it was filtered to allow passage of frequencies between 30 and $3000 \mathrm{~Hz}$. Raw and processed signals were displayed on a Tektronix 5111A storage oscilloscope. Diaphragmatic EMG signals were free of electrocardiographic interference in five of the eight animals and they served as our study subjects. The fast Fourier transform, power spectral density, and Fc of the EMG signal were obtained by utilizing a Hewlett Packard dynamic signal analyzer (model 3561A).

The signal analyzer sampling was triggered by the onset of diaphragmatic EMG activity. The frequency span of the entire power spectrum was from 0 to $1000 \mathrm{~Hz}$, resulting in a time record duration of $400 \mathrm{~ms}$ and a display resolution of $2.5 \mathrm{~Hz}$. The onset of EMG sampling was adjusted in order to include the early phase of the diaphragmatic EMG. It should be noted, thus, that the 400-ms period during which diaphragmatic EMG was sampled represented a majority fraction of the overall period of EMG activity for each inspiration. Twenty inspiratory EMG signals were averaged to obtain the power spectrum for each experimental condition.

The EMG signals were sampled at a rate of $2560 \mathrm{~Hz}$ to satisfy the Nyquist requirement and minimize aliasing. A Hanning window was utilized to minimize leakage. High pass filtering at $30 \mathrm{~Hz}$ was used to minimize motion artifact (11). The $\mathrm{Fc}$ was computed from the power spectrum between 60 and $500 \mathrm{~Hz}$ ( $\geq 95 \%$ of inspiratory diaphragmatic EMG power in 2-day-old infant monkeys is contained between these two frequencies). Fc was calculated and defined as that frequency at which the power above and below it are equal (11).

A minimum of $2 \mathrm{~h}$ passed after surgical preparations before initiation of the study in order to allow ample time for elimination of anesthetic effects (12). The protocol called for measurement of ventilatory variables (4) and diaphragmatic EMG when infants breathed room air and after a 5-min exposure to a hypoxic gas mixture. Two levels of hypoxia were tested in order to arrive at a $\mathrm{PaO}_{2}$ between $20-25$ torr or 17-19 torr after the initial hyperventilatory phase. This typically represented a step change from room air to 12 or $8 \% \mathrm{FiO}_{2}$, respectively. Hypoxemia induced by $12 \% \mathrm{FiO}_{2}$ is sufficient to induce electrocortical depression (13). Since the brain stem might be more resistant than the cortex to a hypoxic insult, the second more severe level of hypoxemia $\left(\mathrm{PaO}_{2}=17-19\right.$ torr $)$ was also tested. A Corning 168 analyzer was used to measure arterial blood bases and $\mathrm{pH}$. Studies were performed during sleep when no rapid eye movements were visible. At least 20 min recovery time was provided between trials with longer periods allowed if arterial blood gas values did not return to normal after this time allotment.

Statistical comparisons were made using the Student's twotailed $t$ test for paired data (Minitab Release 80.1, Penn State Univ., 1980). A $p$ value $<0.05$ was considered to indicate a statistically significant difference.

\section{RESULTS}

As previously reported (4) all the infant monkeys demonstrated a typical biphasic response to both stimulus levels of hypoxia. The late ventilatory decline was due to a fall in tidal volume which occurred in the face of elevated levels of diaphragmatic EMG activity.

Figure 1 is a representative tracing of crural diaphragmatic EMG signals under baseline conditions and after 5 min of
BASELINE

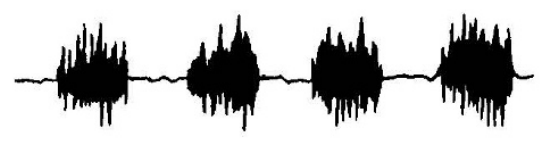

\section{MINUTES OF HYPOXIA}

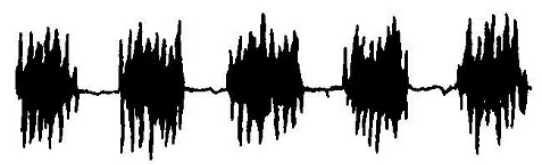

Fig. 1. A representative tracing of crural diaphragmatic EMG signals in one animal under baseline conditions and after $5 \mathrm{~min}$ of hypoxemia demonstrating the absence of EKG contamination.

hypoxemia and demonstrates the absence of EKG contamination.

Figure 2 documents the power spectrum and centroid frequency of one representative monkey under baseline conditions $(A)$, after 5 min of hypoxemia induced by breathing $12 \% \mathrm{FiO}_{2}$ $(B)$, and after 5 min of hypoxemia induced by breathing $8 \%$ $\mathrm{FiO}_{2}(C)$. The $\mathrm{Fc}$ did not decrease during the hypoxic exposures when compared to its baseline value.

Table 1 documents the centroid frequencies of the five infant monkeys under the baseline condition $\left(\mathrm{PaO}_{2}=66 \pm 12\right.$ torr $)$ and after $5 \mathrm{~min}$ of hypoxemia induced by breathing $12 \% \mathrm{FiO}_{2}$ $\left(\mathrm{PaO}_{2}=23 \pm 3\right.$ torr $)$. No significant shift in the $\mathrm{Fc}$ was noted after the 5-min hypoxic exposure $(p=0.79)$.

Table 2 documents the $\mathrm{Fc}$ of the five infant monkeys under the baseline condition $\left(\mathrm{PaO}_{2}=67 \pm 10\right.$ torr) and after 5 min of hypoxemia induced by breathing $8 \% \mathrm{FiO}_{2}\left(\mathrm{PaO}_{2}=18 \pm 1\right.$ torr $)$. Again, no significant shift in the $\mathrm{Fc}$ was noted between these two conditions $(p=0.74)$.

The coefficient of variation of the $\mathrm{Fc}$ for the study animals ranged from 7 to $12 \%$ during the baseline period, from 8 to $15 \%$ during $12 \% \mathrm{FiO}_{2}$ exposure, and from 6 to $19 \%$ during $8 \% \mathrm{FiO}_{2}$ exposure.

\section{DISCUSSION}

This investigation demonstrates that significant changes in the Fc of the crural diaphragmatic electromyogram do not occur during the late ventilatory decline in the biphasic hypoxic ventilatory response in newborn monkeys. Thus, diaphragmatic fatigue, as defined by a decline in the Fc, does not occur during the neonatal biphasic hypoxic response.

It should be noted that our definition of fatigue is limited to the case involving a power spectral shift to lower frequencies. This definition rests on observations that fatigue in limb skeletal muscle is associated with characteristic changes in the power spectrum of the frequency components of the electromyogram. These changes include an increase in the total power, an increase in low frequency power, and a decay in high frequency power (14-16). Similar changes in diaphragmatic electromyogram signals have been noted during loaded breathing and/or fatiguing exercise in adult human volunteers $(8,17-19)$. The mechanisms underlying the spectral shift in the EMG during muscle fatigue are uncertain. Central and peripheral factors may contribute to this phenomenon (20). Central factors may include increasing synchronization and a mean slowing of the motor unit firing rate $(21,22)$. Peripheral factors may include a slowing of conduction in the terminal nerve fibers (23) and a slowing in muscle action potential conduction velocity (24). 

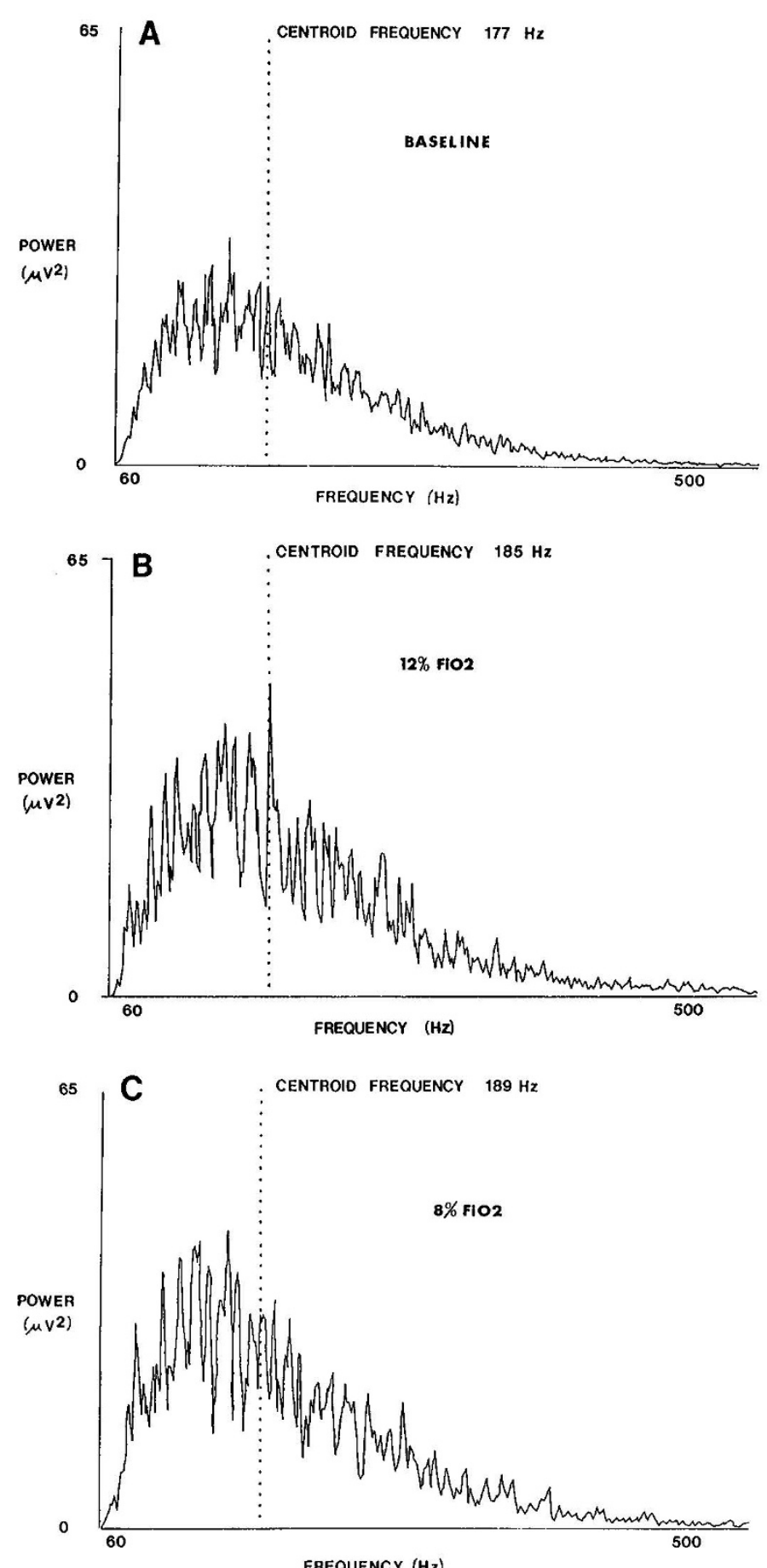

Fig. 2. The power spectrum and centroid frequency of one representative infant monkey under baseline condition $(A)$, after $5 \mathrm{~min}$ of hypoxemia induced by breathing $12 \% \mathrm{FiO}_{2}(B)$, and after $5 \mathrm{~min}$ of hypoxemia induced by breathing $8 \% \mathrm{FiO}_{2}(C)$. The centroid frequency is indicated by the dotted vertical line.

Recent work, however, has raised questions regarding the exact relationship between shifts in the electromyogram power frequency spectrum and muscle fatigue. Sandercock et al. (25) examining single motor unit action potentials during fatigue observed that changes in motor unit action potential amplitude and duration correlated with changes in tension development at high frequencies of stimulation $(80 \mathrm{~Hz})$ but not low frequencies of stimulation $(10 \mathrm{~Hz})(25)$. Since the electromyogram signal is dependent on the summation and cancellation of individual motor unit action potentials, they hypothesized that the electro-
Table 1. Fc determinations baseline versus $5 \mathrm{~min}$ of $12 \% \mathrm{FiO}_{2}$

\begin{tabular}{cc}
\hline $\mathrm{Fc}(\mathrm{Hz})$ baseline & $\mathrm{Fc}(\mathrm{Hz}) 12 \% \mathrm{FiO}_{2}$ \\
\hline 172.5 & 167.5 \\
177.5 & 190.0 \\
185.0 & 190.0 \\
165.0 & 165.0 \\
195.0 & 187.5 \\
& $180 \pm 13^{*}$ \\
\hline
\end{tabular}

* Mean $\pm 1 \mathrm{SD}$.

Table 2. Fc determinations baseline versus 5 min of $8 \% \mathrm{FiO}_{2}$

\begin{tabular}{cc}
\hline $\mathrm{Fc}(\mathrm{Hz})$ baseline & $\mathrm{Fc}(\mathrm{Hz}) 8 \% \mathrm{FiO}_{2}$ \\
\hline 175.0 & 180.0 \\
175.0 & 185.0 \\
190.0 & 187.5 \\
175.0 & 162.5 \\
195.0 & 190.0 \\
& \\
$182 \pm 10^{*}$ & $181 \pm 11^{*}$ \\
\hline
\end{tabular}

$*$ Mean $\pm 1 \mathrm{SD}$

myogram will provide a reasonable estimate of high frequency fatigue (i.e. loss of tension at high frequencies of neural stimulation that results from failure of excitation of skeletal muscle fibers) but an unreliable measure of low frequency fatigue (i.e. loss of tension at low frequencies of neural stimulation that results from a failure of excitation-contraction coupling). Moxham et al. (26) generated in vivo data in support of this hypothesis during their examination of changes in the diaphragmatic electromyogram power spectrum with fatigue in adult humans. They observed that only high frequency fatigue (i.e. a decline in transdiaphragmatic pressure development at high frequencies of phrenic nerve stimulation) was associated with shifts to lower frequencies in the electromyogram frequency spectrum. Low frequency fatigue (i.e. a decline in transdiaphragmatic pressure at low frequencies of phrenic nerve stimulation) was not associated with any shifts in the electromyogram frequency spectrum. Whether a similar phenomenon occurs in the neonate and/or during severe hypoxemia is unknown. Further investigation is needed to define the relationship between electromyographic and mechanical activities within a neonatal context during a documented fatigue state.

Since diaphragmatic fatigue appears to be absent during the neonatal biphasic hypoxic ventilatory response, we suggest that the late ventilatory decline during hypoxia is secondary to a combination of various factors. These include alterations in 1) pulmonary mechanics, 2) diaphragmatic mechanics, and 3) central neural drive. Previous work in our laboratory demonstrated that dynamic lung compliance falls and functional residual capacity increases as ventilation declines during the biphasic response (6). These mechanical changes would account for a reduction in inspired volume for a given level of neural drive in that 1) the lung is less distensible and 2) the diaphragm is in a less favorable force-length configuration making it a less efficient pressure generator. These findings alone could theoretically explain the late ventilatory depression during the biphasic neonatal hypoxic response.

In addition, the small decline in neural activity that does occur after the peak ventilatory response may play an etiological role in the late ventilatory depression particularly since investigators have demonstrated that an unfavorable diaphragmatic forcelength configuration elicits a compensatory increase in central neural drive in adults (27). No such augmentation in central neural drive was observed during the late ventilatory decline in the infant monkey when an adverse alteration in diaphragmatic force-length configuration associated with an increase in func- 
tional residual capacity presumably occurred. This finding may reflect the observation that infants, in contrast to adults, adopt a breathing strategy to limit the extent of change in absolute lung volume, rather than to defend ventilation, at increased lung volume (28).

\section{REFERENCES}

1. Blanco CE, Hanson MA, Johnson P, Rigatto H 1984 Breathing pattern of kittens during hypoxia. J Appl Physiol 56:12-17

2. Cotton EK, Grunstein MM 1980 Effects of hypoxia on respiratory control in neonates at high altitude. J Appl Physiol 48:587-595

3. Woodrum DE, Standaert TA, Mayock DE, Guthrie RD 1981 Hypoxic ventilatory response in the newborn monkey. Pediatr Res 15:367-370

4. LaFramboise WA, Woodrum DE 1985 Elevated diaphragm electromyogram during neonatal hypoxic ventilatory depression. J Appl Physiol 59:10401045

5. Lawson EE, Long WA 1983 Central origin of biphasic breathing pattern during hypoxia in newborns. J Appl Physiol 55:483-488

6. LaFramboise WA, Guthrie RD, Standaert TA, Woodrum DE 1983 Pulmonary mechanics during the ventilatory response to hypoxemia in the newborn monkey. J Appl Physiol 55:1008-1014

7. Watchko JF, LaFramboise WA, Standaert TA, Woodrum DE 1986 Diaphragmatic function during hypoxemia: neonatal and developmental aspects. $\mathbf{J}$ Appl Physiol 60:1599-1604

8. Aldrich TR, Adams JM, Arora NS, Rochester DF 1983 Power spectral analysis of the diaphragm electromyogram. J Appl Physiol 54:1579-1584

9. Godal A, Belenky DA, Standaert TA, Woodrum DE, Grimsrud L, Hodson WA 1976 Application of the hot-wire anemometer to respiratory measurements in small animals. J Appl Physiol 40:275-277

10. Trelease RB, Sieck GC, Harper RM 1982 A new technique for acute and chronic recording of crural diaphragm EMG in cats. Electroencephalogr Clin Neurophysiol 53:459-462

11. Schweitzer TW, Fitzgerald JW, Bowden JA, Lynne-Davies P 1979 Spectral analysis of human inspiratory diaphragm electromyograms. J Appl Physiol 46:152-165

12. Hargrove JC, Heavner JE, Guthrie RD, Morton WR 1980 Age dependent ketamine pharmacodynamics in the pigtail monkey (Macaca nemestrina). Proc West Pharmacol Soc 23:129-133

13. Guthrie RD, Knauss TA, Haberkern CM, Sumi SM, Woodrum DE 1982
Power spectral analysis of the neonatal primate electroencephalogram during acute hypoxemia. Pediatr Res 16:30-34

14. Kadeffors R, Kaiser E, Petersen I 1968 Dynamic spectrum analysis of myopotentials and with special reference to muscle fatigue. Electromyography 8:3974

15. Kwatny ED, Thomas DA, Kwatny HG 1970 An application of signal processing techniques to the study of myoelectric signals. IEEE Trans Biomed Eng 17:303-313

16. O'Donnell RD, Rapp J, Berkhout J, Adey WR 1973 Autospectral and coherence patterns from two locations in contracting biceps. Electromyograph Clin Neuro Physiol 13:259-264

17. Aubier M, Farkas G, DeTroyer A, Mozes R, Roussos C 1981 Detection of diaphragmatic fatigue in man by phrenic stimulation. J Appl Physiol 50:538544

18. Bellemere F, Grassino A 1982 Evaluation of human diaphragm fatigue. J Appl Physiol 53:1196-1206

19. Gross D, Grassino A, Ross WRD, Macklem PT 1979 Electromyogram pattern of diaphragmatic fatigue. J Appl Physiol 16:1-7

20. Kranz H, Williams AM, Cassell J, Caddy DJ, Silberstein RB 1983 Factors determining the frequency content of the electromyogram. J Appl Physiol 55:392-399

21. Jones NB, Lago P 1977 Effect of motor-unit firing time statistics on EMG spectra. Med Biol Eng Comput 15:648-655

22. Lippold OCJ, Redfern JWT, Vuco J 1960 The electromyography of fatigue. Ergonomics 3:121-131

23. Bigland-Ritchie B, Jones DA, Woods JJ 1979 Excitation frequency and muscle fatigue: electrical responses during human voluntary and sustained contractions. Exp Neurol 64:414-427

24. Lindstrom L, Magnusson R, Petersen I 1970 Muscular fatigue and action potential conduction velocity changes studied with frequency analysis of EMG signals. Electromyography 10:34I-355

25. Sandercock TG, Faulkner JA, Albers JW, Albrecht PH 1985 Single motor unit and fiber action potentials during fatigue. J Appl Physiol 58:1073-1079

26. Moxham J, Edwards RHT, Aubier M, Detroyer A, Farkas G, Macklem PT, Roussos C 1982 Changes in EMG power spectrum (high-to-low ratio) with force fatigue in humans. J Appl Physiol 53:1094-1099

27. Green M, Mead J, Sears TA 1978 Muscle activity during chest wall restriction and positive pressure breathing in man. Respir Physiol 35:283-300

28. Stark AR, Waggener TB, Frantz ID, Cohlan BA, Feldman HA, Kosch PC 1984 Effect on ventilation of change to the upright posture in newborn infants. J Appl Physiol 56:64-71 